DOE/ER/40209-22

\title{
QUANTUM THEORY OF FIELDS
}

\author{
Progress Report
}

for Period October 1995 - September 1996.

\author{
Suraj N. Gupta \\ Wayne State University \\ Detroit, Michigan 48202
}

September 1996

Prepared for

U.S. DEPARTMENT OF ENERGY

UNDER CONTRACT DE-FG02-85ER40209

DOE Patent Clearance Granted

Munhf Dorsale

Mark P. Dvorscak

$\frac{1 \cdot 15 \cdot 04}{\text { Date }}$

(630) 252-2393

Office of Intellectual Froperty Law

DOE Chicago Operations Office 


\section{DISCLAIMER}

This report was prepared as an account of work sponsored by an agency of the United States Government. Neither the United States Government nor any agency thereof, nor any of their employees, makes any warranty, express or implied, or assumes any legal liability or responsibility for the accuracy, completeness, or usefulness of any information, apparatus, product, or process disclosed, or represents that its use would not infringe privately owned rights. Reference herein to any specific commercial product, process, or service by trade name, trademark, manufacturer, or otherwise does not necessarily constitute or imply its endorsement, recommendation, or favoring by the United States Government or any agency thereof. The views and opinions of authors expressed herein do not necessarily state or reflect those of the United States Government or any agency thereof. 


\section{DISCLAIMER}

Portions of this document may be illegible in electronic image products. Images are produced from the best available original document. 


\section{Description of Research Activities 1995-1996}

During the period covered by this progress report, we have published the following three research papers:

1. " $B_{c}$ Spectroscopy in a Quantum-chromodynamic Potential Model," S. N. Gupta and J. M. Johnson, Phys. Rev. 'D 53, 312 (1996).

Abstract: We have investigated $B_{c}$ spectroscopy with the use of a quantum-chromodynamic potential model which was recently used by us for the light-heavy quarkonia. We give our predictions for the energy levels and the $E 1$ transition widths. We also find, rather surprisingly, that although $B_{c}$ is not a light-heavy system, the heavy quark effective theory with the inclusion of the $m_{b}^{-1}$ and $m_{b}^{-1} \ln m_{b}$ corrections is as successful for $B_{c}$ as it is for $B$ and Bs.

2. "Gauge-Boson Scattering Signals at the CERN LHC," S. N. Gupta, J. M. Johnson, G. A. Ladinsky and W. W. Repko, Phys. Rev. D 53, 4897 (1996).

Abstract: We have extended our earlier treatment of the gauge-boson scattering with radiative corrections in the standard model at supercollider energies, and computed the rates for gauge-boson scattering modes in $p p$ collisions leading to the final states $W^{+} W^{-}, Z Z(4 l), Z Z(2 l 2 \nu), W^{ \pm} Z$, and $W^{ \pm} W^{ \pm}$. Our results at the CERN LHC energy of $\sqrt{s}=14 \mathrm{TeV}$ for $m_{H}=$ $1000 \mathrm{GeV}$ are compared with those recently obtained by Bagger et al. These results will be useful in the search for the Higgs bosons at supercollider en- 


\section{NOTICE}

This report was prepared as an account of work sponsored by the United States Government. Neither the United States or the United States Department of Energy, nor any of their employees, nor any of their contractors, subcontractors, or their employees, makes any warranty, express or implied, or assumes any legal liability or responsibility for the accuracy, completeness, or usefulness of any information, apparatus, produce or process disclosed or represents that its use would not infringe privately owned rights. 
ergies as well as for experimentally distinguishing the standard model from non-minimal Higgs models.

3. "Relativistic Two-photon and Two-gluon Decay Rates of Heavy Quarkonia," Suraj N. Gupta, James M. Johnson and Wayne W. Repko, Phys. Rev. D 54, 2075 (1996).

Abstract: The decay rates of $c \bar{c}$ and $b \bar{b}$ through two-photon or two-gluon annihilations are obtained by using totally relativistic decay amplitudes and a sophisticated quantum-chromodynamic potential model for heavy quarkonia. Our results for the photonic and gluonic widths of the ${ }^{1} S_{0},{ }^{3} P_{0}$, and the ${ }^{3} P_{2}$ states are in excellent agreement with the available experimental data. The procedures and mathematical techniques used by us for the treatment of the fermion-antifermion bound states are also applicable to other decay processes.

The above record of our publications speaks for itself. Our third paper, in particular, on the relativisitic two-photon and two-gluon decay rates of heavy quarkonia should be considered a classic. In this paper, we have developed a formalism for the treatment of bound-state decays which is far superior to anything in the earlier literature. We have also resolved the longi. standing diffculty of the sharp disagreement between the earlier theoretical values and the experimental data for the decay rates of the paracharmonium $S$ and $P$ states. We have several other decay processes in mind which can also be treated by using our formalism.

An important application of our treatment, which is under active investigation by us, is the decays of the light-heavy quarkonia, especially the $B$ decays. Our treatment is expected to lead to an improved determination of 
the CKM parameter $V_{b c}$.

We have also been making progress in exploring several other problems of current interest which were outlined in our last renewal proposal.

The principal investigator has fully complied with the contract requirements. He has devoted to the project $50 \%$ of his time during the academic year and $100 \%$ of his time during two summer months, and this pattern will be followed during the remainder of the current contract term. 